\title{
Development of public transport coordination systems in the Oryol urban agglomeration: problems and perspectives
}

\author{
Andrei Bodrov ${ }^{1 *}$, Denis Lomakin ${ }^{1}$, Ilia Gagarin ${ }^{1}$ and Andrew Simushkin ${ }^{1}$ \\ ${ }^{1}$ Orel State University, 95 Komsomolskaya str., Orel, 302026, Russia
}

\begin{abstract}
The article presents the structure of the subsystem named "Public transport coordination", which comprises two obligatory modules and one optional. Within the framework of intelligent transport systems (ITS), this subsystem could be put into practice in the Oryol urban agglomeration.
\end{abstract}

\section{Introduction}

In 2018, the national project "Safe and High-Quality Roads" was launched in our country. One of the key measures included in the project is "The implementation of intelligent transport systems providing the automation of traffic management processes in urban agglomerations and cities with a population of over 300 thousand inhabitants" [1].

The local project "Intelligent Transport System of the Oryol urban agglomeration" was highly appreciated by the commission responsible for ranking applications for the provision of interbudgetary transfers to the federal subjects of the Russian Federation for the implementation of intelligent transport systems that provide the automation of traffic management processes in urban agglomerations and cities with a population of over 300 thousand inhabitants. This local project is considered as a part of the bigger federal project "System-wide measures for the development of road infrastructure" of the state programme of the Russian Federation "Development of the Transport Systems" [2].

Within the framework of the aforementioned project, several subsystems of the ITS of the Oryol urban agglomeration are envisaged to be implemented, including the subsystem "Public transport coordination".

\section{Material and methods}

The local project "Intelligent Transport System of the Oryol urban agglomeration" was developed on the basis of "Methods for assessing and ranking local projects in order to implement the intelligent transport systems that provide the automation of traffic management processes in urban agglomerations and cities with a population of over 300 thousand inhabitants" and within the framework of the federal project "System-wide

\footnotetext{
* Corresponding author: bodrov57@gmail.com
} 
measures for the development of road infrastructure" and the national project "Safe and High-Quality Roads" [3]. In accordance with the guidelines provided in the abovementioned Methods, architecture of the urban intelligent transport systems must comprise obligatory modules and subsystems. Additionally, there may be added several optional modules and subsystems. The list of modules and subsystems of the urban agglomeration ITS is presented in Table 1.

Table 1. The list of modules and subsystems of the urban agglomeration ITS

\begin{tabular}{|c|c|}
\hline Obligatory modules and subsystems & Optional modules and subsystems \\
\hline 1 & 2 \\
\hline \multicolumn{2}{|c|}{$\begin{array}{c}\text { SYSTEM LEVEL (Central Platform Modules) } \\
\end{array}$} \\
\hline Coordinated traffic control module & Module issuing special permits for transportation \\
\hline $\begin{array}{l}\text { Configuration module for traffic control } \\
\text { scenario plans }\end{array}$ & $\begin{array}{l}\text { Geographic information system for collection, } \\
\text { storage, analysis and graphical visualization of } \\
\text { data }\end{array}$ \\
\hline Transport offenses administration module & Parking space configuration module \\
\hline $\begin{array}{l}\text { ITS dispatch control module for emergency and } \\
\text { military services }\end{array}$ & V2X network configuration module \\
\hline ITS efficiency control module & Billing module for toll fares and services \\
\hline Roadworks control module & $\begin{array}{c}\text { Module of the electronic integrated traffic } \\
\text { management scheme }\end{array}$ \\
\hline $\begin{array}{l}\text { Centralized traffic participants information } \\
\text { module }\end{array}$ & Module "Digital Twin" \\
\hline Public transport traffic control module & - \\
\hline Transport forecasting and modeling module & - \\
\hline \multicolumn{2}{|c|}{ SUBSYSTEM LEVEL } \\
\hline \multicolumn{2}{|c|}{ Traffic management } \\
\hline $\begin{array}{l}\text { Subsystem for directive control of transport } \\
\text { flows }\end{array}$ & Subsystem for per-lane traffic control \\
\hline $\begin{array}{l}\text { Subsystem for indirect control of transport } \\
\text { flows }\end{array}$ & - \\
\hline Traffic lights control subsystem & - \\
\hline Priority passage subsystem & - \\
\hline \multicolumn{2}{|c|}{ Road user information } \\
\hline $\begin{array}{l}\text { Subsystem for informing road users using DMS } \\
\text { and VMS }\end{array}$ & $\begin{array}{c}\text { Subsystem for informing users of the ITS } \\
\text { subsystem using vehicle on-board devices and } \\
\text { personal devices }\end{array}$ \\
\hline- & Subsystem for interaction with road users \\
\hline \multicolumn{2}{|c|}{ Maintenance of roads and other constructions } \\
\hline Road condition management subsystem & $\begin{array}{l}\text { Subsystem for monitoring the condition of the } \\
\text { road and road infrastructure }\end{array}$ \\
\hline- & $\begin{array}{c}\text { Subsystem for dispatch control of road } \\
\text { maintenance services }\end{array}$ \\
\hline \multicolumn{2}{|c|}{ Control of traffic offences } \\
\hline $\begin{array}{l}\text { Subsystem for transport control and traffic rules } \\
\text { compliance monitoring }\end{array}$ & $\begin{array}{l}\text { Subsystem for monitoring compliance with traffic } \\
\text { rules by pedestrians }\end{array}$ \\
\hline 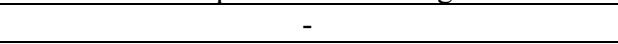 & Subsystem for detection of dangerous goods \\
\hline- & $\begin{array}{l}\text { Subsystem for weight and dimensional control of } \\
\text { vehicles }\end{array}$ \\
\hline \multicolumn{2}{|c|}{ Monitoring of primary events } \\
\hline Weather conditions monitoring subsystem & Environmental parameters monitoring subsystem \\
\hline $\begin{array}{c}\text { Subsystem for monitoring traffic flow } \\
\text { parameters }\end{array}$ & $\begin{array}{l}\text { Subsystem for monitoring pedestrian flow } \\
\text { parameters }\end{array}$ \\
\hline
\end{tabular}


End of Table 1

\begin{tabular}{|c|c|}
\hline \multicolumn{1}{|c|}{ Public transport coordination } \\
\hline $\begin{array}{c}\text { Subsystem for public transport routes } \\
\text { management }\end{array}$ & Subsystem for monitoring the movement of public \\
transport
\end{tabular}

As it can be concluded from the information presented in Table 1, the subsystem "Public transport coordination" consists of two obligatory modules and on optional module, namely:

- subsystem for public transport routes management (obligatory);

- subsystem for "smart stops" management (obligatory);

- subsystem for monitoring the movement of public transport (optional).

\section{Results and Discussion}

Implementation of the subsystem for managing public transport routes will allow to organize, effectively use, track, analyze and plan public transport routes in the Oryol urban agglomeration. Furthermore, this will help to automate the process of collection and analysis of data related to the performance of public transport network. Subsequently, it will be possible to optimize the schedules, traffic flows and improve the quality of service for users of urban public transport system.

The subsystem for public transport routes management will provide:

- creation and optimization of public transport schedules, forecasting and planning of routes;

- continuous monitoring of the compliance of the actual time and location of public transport with the time and location indicated in the approved route schedules;

- optimal organization of the route when: a) the actual time deviates from the time indicated in the schedules, b) environmental conditions change (fog, ice, etc.), c) traffic conditions on certain directions or routes change during the day, 
d) traffic disruption due to long delays on lines or absence of public transport for technical or other reasons occurs;

- optimal use of reserve transport and coordination of traffic with other types of passenger transport;

- information support for decision-making process when organizing public transport;

- presentation of data in the form of reports, preparation of daily reports on the public transport movement and analysis of presented parameters.

The following blocks are proposed to be implemented within the subsystem for public transport routes management:

- client subsystems that provide an optimal interface for interaction with users of the system;

- top-level services - server subsystems implementing the logic of business processes, oriented on working with external entities, solving the problems of dispatching other services by solving business problems;

- technological services - server subsystems designed to develop software functions necessary for solving business problems, other transport subsystems;

- terminal software components that provide interface and control functions of the terminal installed on the objects being monitored;

- interaction services that provide information exchange by transferring and receiving aggregate data from third-party (adjacent) systems.

The subsystem for managing public transport routes must have the structure that would ensure the realization of the main monitoring functions and that will include:

- management of public transport routes, creation and optimization of schedules;

- dispatch control of the schedule and public transport routes.

Data collected by the subsystem for managing public transport routes may be used for various purposes, i.e.:

- for displaying the location of public transport on the route;

- keep tabular records of public transport routes.

The use of various visualization options for this information will make it possible to create different decision-making support systems for dispatchers, adapted to specific tasks.

The subsystem for managing public transport routes will allow the end user to maximize the utility by using the main options of managing and monitoring public transport in a tailor-made workspace of the subsystem.

Creation of the subsystem for "smart stops" management will allow to manage and analyze passenger traffic in the Oryol urban agglomeration, passenger flows at stops, verify automation of collection and processing of the analytical data related to the performance of public transport network.

The subsystem for "smart stops" management will ensure:

- organization of comprehensive passenger information at the stops about the time of arrival of public transport, about the numbers of routes and types of public transport running on this line;

- management, monitoring, operational control, accounting and forecasting of the passenger flows at public transport stops;

- informing passengers about the operation of public transport, namely:

1) changes in schedule;

2) changes in routes;

3) changes related to tariffs and fares;

4) occurrence of criminal and lor emergency situations; 
- providing data for dispatch centers about locations and technical parameters of stops to optimize public transport;

- providing data for dispatch centers for analysis, monitoring and forecasting of passenger flows and for the eventual modifications in public transport operation;

- generation of summarized information on the technical condition of stops (analysis of technical state and capacity);

- presentation of data in the form of reports.

The subsystem for "smart stops" management has to include the following blocks:

- client subsystems that implement the interface for interacting with system users;

- top-level services - server subsystems implementing the logic of business processes, oriented on working with external entities, solving the problems of dispatching other services by solving business problems;

- technological services - server subsystems designed to develop software functions necessary for solving business problems, other transport subsystems;

- terminal software components that provide interface and control functions of the terminal installed on the objects under monitoring;

- interaction services that provide information exchange by transferring and receiving aggregate data from third-party (adjacent) systems

The subsystem for "smart stops" management ought to have the structure ensuring the implementation of the main monitoring functions and that will comprise:

- management of public transport "smart stops";

- monitoring of passenger flows at stops and the state of public transport operation, monitoring the capacity of stops;

- dispatch control to monitor the movement of public transport.

All data collected and generated by the subsystem can be subsequently applied for different purposes, for example:

- to display the location of objects (stops / passenger flows) on a digital map;

- to keep tabular records of the state of passenger flows at public transport stops;

- to calculate and analyze statistics (time of stop, number of passengers, etc.).

As in the case of the subsystem for managing public transport routes, the use of various options and tools to visualize this information will allow to provide different decisionmaking support systems for dispatchers, which will be adapted to specific tasks.

Pavilions at public transport stops are proposed to be equipped with a complex of advanced ITS-related technologies [4, 5]:

1. Information displays. They present the information about the movement of public transport along the route and are constantly updated in accordance with the situation on the road, the current location of the vehicle. Displays show as well the real time of arrival of transport, routes and types of public transport arriving at the stop, the current time, temperature, date and information messages from the city authorities and emergency services.

2. Interactive terminal diagram / map, which displays the current location of the passenger and the transport, as well as the location of the destination point. It allows passengers to select the best travel option by automatically calculating parameters of the desired route, presenting type of public transport, the interval between vehicles, transfer points (from one route to another / from one type of transport to another). With a use of a search bar, a passenger will have a possibility to type any landmark or address within the city limits, which will facilitate the navigation. 
3. Mobile device chargers. They will allow passengers to charge mobile devices at stops via the USB port. Different types of USB ports will be installed for the possibility of charging various mobile devices.

4. Wi-Fi access points will enhance the experience and comfort for passengers waiting for transport, who could use the Internet access free of charge.

5. Energy Saving LED Lighting.

6. Loud-speaking devices for persons with handicap.

7. Video registration and surveillance system. It is necessary to ensure safe conditions for passenger at bus stops and in places where there is a potential danger to pedestrians. The system records what is happening at / near the public transport stop - a video camera is installed on the bus stop pavilion. A video camera records the fact of a vehicle arrival, the actual time of arrival, as well as the registration number of a vehicle, which also allows to detect the movement of illegal transport. It also records how passengers get on/off a vehicle and the number of passengers at the public transport stop. More advanced surveillance systems may also feature facial recognition software, which, for example, can be useful when searching for criminals.

8. Emergency button, which is designed to call the emergency services (police units / ambulance / firefighters).

9. Ticket vending machines. They will be installed for the sale of public transport tickets and will provide the possibility to pay by cash, coins and bank cards (also contactless).

Optional subsystem for monitoring the movement of public transport implements the functionality of the ITS in the operation, planning and management of public transport. The functionality of the subsystem allows to track the movement of the public transport in the Oryol urban agglomeration.

The main element of the subsystem is the regional navigation and information system (RNIS), which ensures the reception of telematic data from urban municipal and commercial public transport of the Oryol urban agglomeration (buses, trolleybuses, trams). In addition, there is implemented the reception of data on the assignment of vehicles to routes $[6,7]$.

The subsystem has a modular structure in which, if necessary, you can add modules or disable unused ones. The block diagram of the subsystem is shown in Figure 1. 


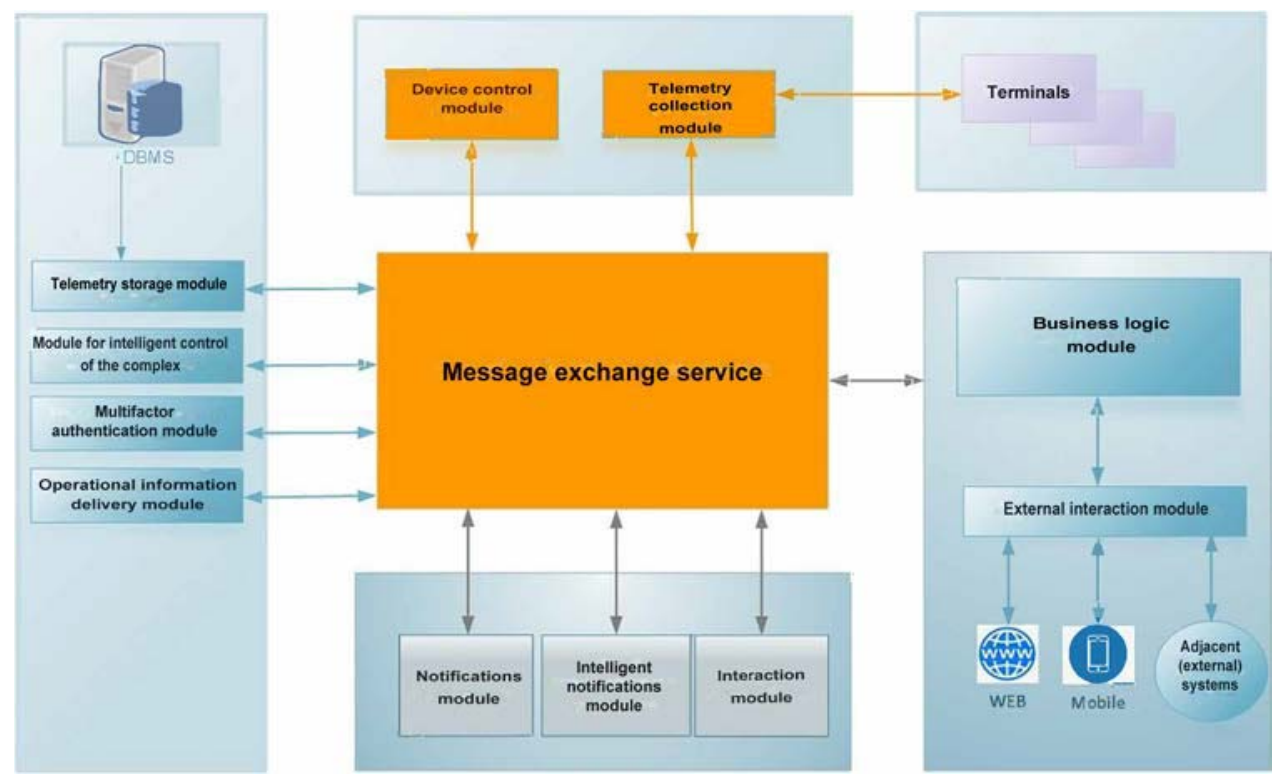

Fig. 1. Structural scheme of the subsystem for monitoring the movement of public transport

The subsystem for monitoring the movement of public transport will allow to display the location of public transport on a digital map, distribute signals/commands and reference information to the dispatcher in case of any incidents. The subsystem will make possible the transmission of text messages and active interference by, for instance, blocking doors and engine of a vehicle. The use of various visualization options for this information would allow to create dedicated systems to assist the dispatcher in decision-making.

\section{Conclusion}

The interaction of the proposed subsystems with adjacent (external) systems is performed directly with an aid of special software installed within the subsystem, thereby providing the software interfaces needed to carry out the tasks.

The implemented solutions ensure the automated data exchange between the technological sites of the subsystem and the corresponding equipment of adjacent (external) systems, processing of the data received by the subsystem, visualization of the relevant information for the respective AWPs of operators and dispatchers.

Modern industrial database management systems (DBMS) such as PostgreSQL or MongoDB are planned to be used for data storage.

Information exchange between subsystems should be carried out using standardized protocols and exchange formats.

\section{References}

1. Resolution of the Government of the Russian Federation of December 21, 2019 No. 1762 "On approval of the rules for the provision and distribution in $2020-2024$ of interbudgetary transfers from the federal budget to the budgets of the federal subjects of the Russian Federation the implementation of intelligent transport systems providing the automation of traffic management processes in urban agglomerations and cities with a population of over 300 thousand inhabitants, within the framework of the 
federal project "System-wide measures for the development of road infrastructure" of the state programme of the Russian Federation "Development of the transport system" (2019)

2. Bodrov A.S., Kulev M.V., Devyatina D.H., Lobunceva O.A. Assessment of the readiness of the Oryol urban agglomeration for the implementation of intelligent transport systems, The world of transport and technological machines, № 3 (70). -pp. 64-72 (2020)

3. Order of the Ministry of Transport of the Russian Federation of March 25, 2020 AK60-r "On approval of the methods for assessing and ranking local projects in order to implement the intelligent transport systems that provide the automation of traffic management processes in urban agglomerations and cities with a population of over 300 thousand inhabitants" and within the framework of the federal project "Systemwide measures for the development of road infrastructure" and the national project "Safe and High-Quality Roads" (2020)

4. GOST 56294-2014. Intelligent transport systems. Requirements for the functional and physical architecture of intelligent transport systems (2014)

5. Zankaziev S.V. Scientific foundations and methodology for the implementation of intelligent transport systems in the automobile and road complexes of cities and regions: doctoral thesis. Moscow, 450 p. (2012)

6. Order of the Ministry of Transport of Russia dated April 18, 2019 No. 114 "On approval of the Road traffic monitoring procedure" (2019)

7. The decision of the Oryol Council of People's Deputies of February 03, 2016. No. 6/0081 GS "On the establishment of the management of municipal services and transport of the administration of the city of Orel" (2016) 